\title{
Online searching as apprenticeship
}

Young people and web search strategies

\author{
Matthew Pearson \\ School of Education and Professional Development, University of Huddersfield, Queensgate, \\ Huddersfield, HD1 3DH, UK; m.j.pearson@hud.ac.uk
}

Abstract: To participate in the Information Society, it is necessary to acquire online searching skills. Despite the promise of improved searching software and the promises of instant access to information made by the search engines themselves, the process still requires human cognition. Many studies of searching behaviour have been made and are summarised along with a report of current research on group interviews with 10 year-old school children. Attitudes to searching the web and negotiating the various digital repositories of information available to them provide valuable clues about children's elearning. A significant finding was the lack of distinction made between resources held on local machines, those on the school network and those on the Internet itself. Analysed from a phenomenographic point of view, it appears that young people are concerned about protecting their own data and privacy, and often those concerns override the need to find new information. Searching was not seen as an activity in its own right; instead, young people concentrated on identifying sources that were usable in a given context. Also of importance was the role of social collaboration, both with siblings and parents, in web searching.

Key words: elementary education, learning styles, social contexts, research

\section{INTRODUCTION}

An information society can only function when citizens are able to gain free access to information, and shape it for their own ends - search and use retrieval skills, display the ability to process information, make sense of it, and manipulate it into new forms. Understanding how children become enculturated into such practices is the central theme of this essay. The World

The original version of this chapter was revised: The copyright line was incorrect. This has been corrected. The Erratum to this chapter is available at DOI: 10.1007/978-0-387-35668-6_17 
Wide Web (WWW) is currently one of the most tangible manifestations of our struggle with information: A frontier where we encounter the enormity of the information on the Internet in all its disorganised glory. Despite the hype that creates metaphors such as "information at your fingertips", or that conceptualises the web as an online library with an innate sense of order, the web is a complex and chaotic space, and our interactions with it are far from straightforward. Dreyfus (2001), drawing on the philosophy of MerleauPonty, discusses how our physical bodies allow us to make sense of the world and how those intuitive heuristic processes that are a function of our physical being in the world are dislocated in virtual settings. He continues his philosophical essay by examining the failure of computer scientists to produce intelligent search instruments for the web, and deconstructs the promise of agents powered by Artificial Intelligence (AI) that can search the web and bring relevant information straight back to our desktops:

There is a vast and ever-growing field of information out there, and it looks like our only access to it will have to be through computers that don't share our bodies, don't share our world and so don't understand the meaning of our documents and web sites. (Dreyfus 2001)

Dreyfus, stoutly refusing to accept the promises of AI, reminds us that searching the web will continue to require human skills, knowledge and perhaps even guile. The search engines, despite their promise of information on demand, are nothing more than unthinking brutes, delivering thousands of pages that contain certain words but do not enable us make sense of what has been retrieved. According to Dreyfus, making sense of information and sorting it into usable forms will be a task for human cognition for many years to come. And so the ability to search the web for relevant information may become one of the central skills for participants in the information society.

Moreover, given the rhetorical promises attached to young people, in which they are constructed as the next generation of cyber citizens and the natural heirs of a digital future, it is important that we find out how children learn to search the web and navigate their way around complex information spaces. This entails more than just noting which search engines they use, how they organise their search behaviour and how they develop criteria for successful searches. We need to look beyond the procedural aspects of searching, and understand the ways in which young people represent the information spaces through which they navigate and how they harness cognitive processes to conduct searches. 


\section{CHILDREN'S SEARCHING STRATEGIES}

Given the importance of finding what we need to find on the web, not surprisingly there is already a considerable amount of research on searching behaviour, including some studies done with children. Studies fall broadly into three categories: The first category consists of studies that seek to explain search behaviour and analyse search strategies in terms of their constituent components (for example, White and Iivonen 2001); the second category includes studies where the searching of experts is compared with less-experienced searchers "newbies" (Hölscher and Strube 2000); the third category includes studies involving the development of new software or tools to assist in searching (Spink 2002).

A useful summary of studies on web searching can be found in HsiehLee (2001), reporting on most of the work done to date and highlighting the work of Bilal (1998), who found notable weaknesses summarised by HsiehLee:

... although they understand the given task, children did not search efficiently or effectively and their search paths revealed frequent looping, back-tracking and poor navigation (Hsieh-Lee 2001).

Children seem to search the web in an ad hoc and random way, and there is a faint tone of reproach, an undercurrent of criticism for feckless youth who will not adopt appropriate search strategies. But perhaps children are serving an apprenticeship as information retrieval experts during this stage, and, true to the form of apprentices, they sometimes cut corners, fail to realise what is important and don't always work with the fastidious exactness of the masters.

My work with children searching the web suggests that they do have many sophisticated searching skills, but expecting them to reach adult competence, and measuring them against this standard is not helpful in understanding how they learn to search (Pearson, 2002). In fact this paper will argue that children who have been brought up with the Internet and the web do not immediately perceive a difference between searching on the web and searching other digital repositories. So research into searching behaviour in different ways might take a more holistic view of information retrieval, and not one which concentrates on the web alone.

Studies of searching behaviour that are modelled too closely on adults' interactions with the web may fail to account for fundamental differences in the ways in which children conceptualise the web. The research on searching behaviour and the efforts at improving the quality of search strategies is likely to grow dramatically as policy makers, software designers, 
educationalists, and any one else with a stake in the information society, realise that unless people are able to find and use information, all the promise of a virtual economy comes to naught.

Facer, et al. (2001) have examined in detail the discursive structures that surround children's computer use, as well as some of the contradictions which constrict children as both experts, fully at home in the digital world and able to exercise agency and self-control, and, simultaneously, as passive consumers of digital culture.

The act of searching the web is a curious mixture of procedural activity (find a search engine, enter key terms, review results, click links to visit sites), high level cognitive endeavour (the information density on an average page of search results is extremely high and requires a great deal of processing), and pure stochastic incidence (sometimes you just hit on the correct site by chance). The technology of the search engine presents itself as being easy to use, and the popular search engine Ask Jeeves employs the conceit of a butler who can be sent off on data collection "errands" and who dutifully delivers the goods right to our desktops. Any hint of the weaknesses in web searching and of promises which cannot be kept are eschewed from the interface altogether. Advanced search engine features such as Boolean operators and domain specific searches are nearly always not given on the front page of the site, and require the click of the "advanced" button. The search itself takes only seconds and somehow the list of hits, although constructed at lightning speed, has an authority which makes us respond as if to a definitive list of sites.

Expert searchers, because they can draw upon knowledge of how search engines operate, can move beyond that allure of authority and will perform repeated searches, refining terms and adjusting criteria to improve relevance. Hale and Moss (1999) coined the term "hazyspace" to capture the sense of a list of information which may or may not be relevant to the task in hand and which needs considerable expertise on the part of searchers to reach their teleological goals.

So, despite the popular view of the web as an encyclopaedia, digital library or information store, where searching is a transparent and irrelevant precursor to getting our hands on the information, searching is what the web is all about. Only users who can navigate through the complex of information will be able to take a full part in the Information Society. Searching may seem like consumption of information, the web equivalent of flicking channels on a satellite TV receiver until something interesting is found, but it is an active wrestling with information requiring an active cognitive engagement with the material and a huge wealth of supporting skills and knowledge. Despite discourses that construct our searching as 
trouble-free interactions modelled on transparent consumption, web searching is a difficult business.

\subsection{Research on children's interactions with information sources}

Early stages of research conducted with 9 and 10 year-old school children in the United Kingdom (Pearson 2002) is predicated on constructivist principles, and the design of the methodology has been driven by the belief that children actively construct mental representations of the technology they encounter. The research also shows that children's representations further developed their expertise. Folk psychology has already enshrined such principles in the popular imagination by saying children do not need to "read the manual", they "just pick it up as they go along", and "they are the only ones who can program the video."

The early plan for the present research study was to use a phenomenographic approach to data collection and analysis. Pioneered by Marton (1994), the research method seeks to categorise ways in which phenomena are experienced and, from the categorisations, draw conclusions about learning. Phenomenography seeks to differentiate between deep and surface learning, and by focussing on the perceptual efforts of the learners, attempts to draw distinctions between the core, fields and fringes of experience.

The first data collection encounters with the young people took the form of very informal group interviews in the computer suite of their school. Pressure on schools to achieve and maintain high Standard Assessment Test (SAT) scores has made it difficult to gain access to children, especially where access may entail taking them away from core curriculum subjects. So I visited the school during lunchtimes, when a group of 9 and 10 year-old pupils were allowed to use the computers and participate in the research. The early encounters had a deliberate lack of structure as I sought to understand a little more about how the children were using the computers and what issues were important for them. In conversation with them it became clear that searching the web was not an important issue and some even expressed surprise that I wanted to know about it. What also emerged was the children's lack of differentiation between resources that were available online and those stored on local hard drives or the school network. In response to a direct question about how they found things on the web, the following answer was given:

When you need to find something out, then click on this (agitates mouse pointer over the icon which launches MS 
Encarta), or just go here (indicates the web browser icon), go to Ask Jeeves, and then you'll just get straight to the stuff .... (male age 10, Pearson 2002)

For him, the information available from the desktop of the school computer did not fall into the categories of local, network and Internet resource. The phrase "go straight to the stuff" combines both immediacy and informality, and demonstrates that at this point the boy did not see searching as a discrete activity. Indeed, when pressed to explain a little more about the various sources the same student replied:

Encarta is like the best bit of the Internet on these machines, these bits (motions towards a web page which has been loading for the last 5 minutes and has now stalled) take forever to load, but Encarta comes up really quickly. (Pearson 2002)

His point of view is not factually correct. The Encarta CD runs on the school network (hence the retrieval speed), and although there are links outward to the Internet, it is essentially a local resource. In phenomenographic terms, the children did not experience the various sources of information available to them as differentiated phenomena. Whether an information source was online or local or networked was a fringe concern, and the core of their cognitive activity was directed towards finding information that was accessible. In the school where the research was taking place, Internet access had been poor for many months, and many of the young people interviewed had ceased to bother opening browsers, concentrating instead on locally networked resources.

The failure to discriminate between different aspects of the digital network coincides with the findings of Somekh and Pearson (2001), who used concept maps to explore 10 year-old children's mental representations of digital technology. The study found that children drew maps with very high levels of interconnectivity and elements belonging to the Internet were connected with other devices and other networks. Somekh and Pearson (2001) also found many concept maps in which mobile phones, games consoles and even cars and watches were all linked to a central node represented by an iconic globe character which represented the Internet. Distinctions between various elements of networks and factual elements representing the true nature of connectivity were rare and most children's maps focussed instead on how various elements of technology are becoming joined up by networking.

As the group interviews and informal data collection sessions progressed (there were a total of five over a period of two weeks), gradually 
the concerns of the young people regarding their use of ICT emerged. An entirely different agenda from that of searching for information surfaced, one that foregrounded the young people's own data and work, and was tied in with their concerns about safety and privacy. All children had access to their own server space on the school network, referring to that space as the gateway, and they jealously guarded their passwords and user privileges. This anxiety about keeping data secret, or of circumventing possible unauthorised access by other pupils or surveillance by teachers, often extended into the home:

On my dad's machine I have my own folders. I learned how to put a password on them and now only I can see inside. My dad didn't know how I'd done this, but I won't let him have the password, I don't want him looking at my stuff. (female, age 10, Pearson 2002)

The theme of data security surfaced again and again. It shows that the children's engagements with ICT were often driven by the need to make a personal space and retain possession of their own data, rather than searching the web for information. Searching the web was seen as an important activity by most but few of the participants in the study could explain how search engines worked or reflect in any detail on their searching behaviour. Another significant theme that emerged during the group interviewing process was the role of collaboration, especially in the home, in finding materials on the web. The following quotations, from two children, point to the roles of parents and siblings in helping children of this age locate web pages:

If I want something, my Dad just goes click click click (mimes someone typing very fast on the keyboard), and there it is. He then saves it onto my special page which has all my favourite sites on. (female, age 10, Pearson 2002)

Me and my brother look for things together, PlayStation games or CDs or sometimes football results. He controls the mouse, and we decide where to click next. (male, age 9, Pearson 2002)

\section{CONCLUSION}

Distinctions between the Internet, the World Wide Web, local and network resources were not routinely made by the young people in this 
study. Rather than categorising resources by type, they saw only the accessibility of information from the school's computers as being the issue. Thus CD-ROMs and local resources were favoured over Internet resources primarily because of the speed of loading of the former, and the glacially slow download of the latter. The children interviewed all expressed considerable frustration at the failings of the school's Internet connection, and eight out of the ten, who had regular access to the Internet at home, made direct and unfavourable comparisons between ease of access in the home and the failure of the school network. More research is needed in this area, and it will be necessary to understand more about how children mentally represent the various digital resources available to them and how they make decisions about utilising them. Finally, to understand more about how young people search for resources, it will be necessary to capture the social component of searching. That aspect, all too often lost in experimental studies which force users into individual modes of action, is clearly important, and may tell us much more about how young people become enculturated into information societies.

\section{REFERENCES}

Bilal, D. (1998) Children's search processes in using World Wide Web search engines: An exploratory study. In C. M. Preston (ed.) Proceedings of the $61^{\text {st }}$ ASIS Annual Meeting. Medford, NJ: Information Today 45-51.

Dreyfus, H. L. (2001) On the Internet. Routledge: London.

Facer, K., Furlong, J., Furlong, R., and Sutherland, R. (2001) Constructing the child computer user: From public policy to private practices. British Journal of Sociology of Education 22 191-108.

Hale, G. and Moss, N. (1999) Methodological issues in using grounded theory to investigate Internet searching. Paper presented at the European Conference Educational Research $25^{\text {th }}$ conference, September 1999.

Hölscher, C., and Strube, G. (2000) Web search behaviour of Internet experts and newbies. Computer Networks 33 337-346.

Hsieh-Yee, I. (2001) Research on Web search behavior. Library and Information Science Research 23 167-185.

Marton, F. (1994) Phenomenography. In T. Husen and T. N. Postlethwaite (eds.) The International Encyclopedia of Education. Oxford: Pergamon 8 4424-4427.

Pearson, M. (2002) Children's search strategies. Unpublished paper.

Somekh, B. and Pearson, M. (2001) Children's representations of new technology: Mismatches between the Public Education Curriculum and socio-cultural learning. Paper presented at the American Educational Research Association Annual Conference: Seattle, WA, April 2001.

Spink, A (2002) A user-centered approach to evaluating human interaction with Web search engines: An exploratory study. Information Processing and Management 38 3 401-426.

White, M. D. and livonen, M. (2001) Questions as a factor in Web search strategy. Information Processing and Management 375 721-740. 


\section{BIOGRAPHY}

Matthew Pearson studied English Literature before completing a Ph.D. in modern literary theory. He then trained as an English teacher and taught in sixth form colleges. During that time he developed an interest in ICT and began to experiment in using technology for teaching purposes. He is now a senior lecturer at the University of Huddersfield, where he is course leader for a Masters degree in Multimedia and Education. His research interests are now centred on the ways young people use digital technologies. 